\title{
O capitalismo dependente, o subfinanciamento do SUS e as iniquidades no acesso às vacinas para o enfrentamento ao contexto pandêmico da COVID-19 no Brasil
}

\author{
Dependent capitalism, the SUS underfunding and the inequities in access to vaccines to confronting \\ the COVID-19 pandemic context in Brazil \\ Maria Eduarda Maia Vilar*, Ana Carolina Souza Torres \\ Como citar esse artigo. VILAR, M. \\ E. M; TORRES, A. C. S. O capitalismo \\ Resumo
}

dependente, o subfinanciamento do SUS

$\mathrm{e}$ as iniquidades no acesso às vacinas

para o enfrentamento ao contexto pandêmico da COVID-19 no Brasil. Mosaico - Revista Multidisciplinar de Humanidades, Vassouras, v. 12, n. 3, p. 23-29, set./dez. 2021.

Nota da Editora. Os artigos publicados na Revista Mosaico são de responsabilidade de seus autores. As informações neles contidas, bem como as opiniões emitidas, não representam pontos de vista da Universidade de Vassouras ou de suas Revistas.

No mês de junho de 2021, o Brasil alcançou a marca de 500.000 mortos por COVID-19. No país, existe a exclusão de ampla parcela da população nacional da ordem econômica, social e política, sendo subordinado ao capitalismo mundial (heteronomia), refletindo na saúde pública da população. No conceito de sindemia, as interações biológicas e sociais são importantes para o prognóstico, o tratamento e a política de saúde; a combinação destes fatores amplifica o dano causado pela doença infecciosa. $\mathrm{O}$ SUS, enquanto sistema universal e igualitário tem papel fundamental no combate à pandemia. Desta forma, mesmo com todas as fragilidades, conseguiu responder à pandemia da COVID-19, evitando o colapso do sistema assistencial do país e maior número de mortos. Este trabalho objetiva correlacionar, de forma sucinta, a teoria do capitalismo dependente de Florestan Fernandes, o subfinanciamento do SUS, às iniquidades na distribuição e no acesso à vacina contra COVID-19 e ao enfrentamento da pandemia (ou sindemia?) da COVID-19 no Brasil.

Palavras-chave: Sistema Único de Saúde. Covid-19. Sindemia. Capitalismo. Iniquidade em Saúde.

\begin{abstract}
In June 2021, Brazil surpassed the mark of 500,000 deaths by COVID-19. In the country, a large portion of the national population is excluded from the economic, social, and political order, being subordinated to world capitalism (heteronomy), which reflects on the population's public health. In the syndemic concept, biological and social interactions are essential for the prognosis, treatment, and health policy; these factors combined increase the damage caused by the infectious disease. The Unified Health System (SUS), as a universal and egalitarian system, has a key role in fighting the pandemic. In this perspective, despite all its weaknesses, it managed to respond to the COVID-19 pandemic, preventing the country's health system from collapsing and an even greater number of deaths. This study aims to briefly correlate Florestan Fernandes' theory of dependent capitalism, the SUS underfunding, the inequities in the distribution and access to COVID-19 vaccines, and the fight against the COVID-19 pandemic (or syndemic?) in Brazil..

Keywords: Unified Health System. COVID-19. Syndemic. Capitalism. Health Status Disparities.
\end{abstract}

\section{Introdução}

No mês de junho de 2021, o Brasil alcançou a marca de 500.000 mortos por COVID-19 (BRASIL, 2021). O objetivo deste trabalho não é explicar as políticas desastrosas e as omissões que culminaram com este resultado. Pretende-se correlacionar, de forma sucinta, a teoria do capitalismo dependente de Florestan Fernandes, o subfinanciamento do SUS, ao enfrentamento à pandemia (ou sindemia?) da COVID-19 no Brasil e refletir acerca das iniquidades na distribuição e no acesso às vacinas contra COVID-19.

$\mathrm{Na}$ concepção do Capitalismo Dependente de Florestan Fernandes, a concentração de renda, de prestígio social e de poder ocorre nos extratos estratégicos para o núcleo hegemônico de dominação externa. Há existência concomitante de estruturas políticas, econômicas e socioculturais em momentos históricos distintos, em recíproca dependência e necessárias, de modo igual para que se articulem e ampliem toda a economia. Esse formato se configura com exclusão socioeconômica e política de grande parte da população nacional, caracterizando condição dinâmica e estrutural à manutenção da expansão de todo o sistema. Para o autor, o país, sendo heterônomo, está subordinado "aos interesses do capitalismo mundial e às políticas de ajustes, determinadas pelas agências internacionais", isto favorece a manutenção de um

Afiliação dos autores:

Instituto de Saúde Coletiva, Universidade Federal da Bahia, Salvador, BA, Brasil.

* Email de correspondência: : vilar.eduarda@gmail.com 
regime com grandes desigualdades sociais (SANTOS, 2018 apud FERNANDES, 1981).

O conceito de sindemia surgiu na década de 1990, com Merrill Singer, Emily Mendenhall e outros. Esta abordagem ressalta que as interações biológicas e sociais são importantes para o prognóstico, o tratamento e a política de saúde, a combinação destes fatores amplifica o dano causado pela doença infecciosa. Horton (2020) sugere que a pandemia da COVID 19 não é pandemia, mas sindemia, quando uma doença infecciosa não pode ser considerada apenas como um agente etiológico isolado, mas como uma interação entre fatores políticos, sociais, econômicos, gerando desigualdades sociais, má distribuição de renda, falta de moradia, saneamento e outros bens essenciais.

Apesar da resposta do Sistema Único de Saúde (SUS), a pandemia expôs as vulnerabilidades do sistema, como alguns municípios não conseguiram simultaneamente atuar na crise sanitária e manter os serviços da atenção básica e fazer a vigilância epidemiológica efetiva, a exemplo do rastreio de casos e contactantes (CIORRA, 2020). Para Fraga (2020), o SUS tem avaliação histórica negativa pela opinião pública, o foco central da insatisfação são as longas filas e a demora no atendimento, resultado, muitas vezes, de uma atenção básica e de regulação de fluxos assistenciais ineficientes, restringindo este serviço à população. Porém, os reais problemas, como subfinanciamento crônico (menos que 4\% do PIB) e má gestão, além das desigualdades regionais na quantidade e qualidade da força de trabalho, ainda, precisam ser debatidos (FRAGA, 2020; COLLUCCI, 2021).

\section{Breve história do capitalismo no Brasil e no mundo}

A segunda e terceira parte do trabalho, no qual foram abordados aspectos do capitalismo no Brasil e no mundo, a Constituição de 1988 e o direito à saúde no Brasil, foram baseadas na obra: $A$ ampliação do processo de privatização da saúde pública no Brasil, de Júlia Amorim Santos.

Santos (2018), ao discutir acerca da gênese do capitalismo em países europeus que foram berço da Revolução Industrial e da formação do capitalismo brasileiro, ancora-se em Fernandes (2008), o qual aponta distinções nesse processo. Para ele, a Europa contou com bases políticas e materiais que ampliaram as propriedades do capitalismo e caracterizou-se por sucessivos movimentos de luta de classes presente nesses países, por revoluções nacionais, urbanas, agrárias, industriais. A Revolução Burguesa, a luta de classes e o capitalismo nesses países podem conduzir à independência socioeconômica e cultural na presença de vontade nacional que se assegure coletivamente, de forma política, e que priorize como objetivo uma sociedade nacional com autonomia (FERNANDES, 2008).

Com o advento da Revolução Industrial e, consequentemente, ascensão do capitalismo, as políticas sociais passaram a ser "frutos" das lutas de classe e do desenvolvimento da intervenção estatal. As políticas sociais são "expressões multifacetadas da questão social do capitalismo" (SANTOS, 2018, p. 40), são influenciadas por três fatores: pelos movimentos de luta de classe, pela desigual participação na distribuição de riqueza social e pela valorização e acumulação do capital (BEHRING; BOSCHETTI, 2011; MONTAÑO, 2002).

Com a crise do capital na década de 1970, houve reação da burguesia a esta crise, com reorganização do modo capitalista e reestruturação produtiva, conhecida como "era da acumulação flexível". Este período foi marcado pela incorporação de novas tecnologias, desterritorialização, deslocamento de unidades produtivas para a periferia do capitalismo, terceirização dos espaços de produção e dissolução da unidade constitutiva do Estado e do capital nacional (PAULO NETTO; BRAZ, 2009; SAMPAIO JR, 2007; BEHRING, 2008; SANTOS, 2018). Observaram-se como consequência desta reorganização: financeirização do capital, relações orientadas pelo capital portador de juros, capital fictício determinando as relações sociais, desemprego crescente e precarização do trabalho, prejuízo à efetivação de políticas públicas universais no aspecto internacional, aumento das políticas de liberalização do mercado, perda de direitos conquistados pelos trabalhadores, corte nos gastos sociais e nas medidas legais restritivas aos movimentos sociais (BEHRING, 2008; BEHRING; BOSCHETTI, 2011; MENDES, 2019; PAULO NETTO; BRAZ, 2009).

Para Fernandes (2008), o processo de formação do capitalismo brasileiro se distingue dos países europeus, pois contou com direcionamento político sob monopólio de burguesias conservadoras e dependentes. Nesse contexto, foram restringindo a participação política dos setores populares, associandose estrategicamente com o imperialismo. Como consequência, foi perdurando o subdesenvolvimento, a dependência, limitando a possibilidade de conciliar capitalismo e integração nacional, como nos países de capitalismo central.

Santos (2018) segue em diálogo com a problemática trabalhada por Fernandes (2008), o qual pensa o Brasil e o respectivo subdesenvolvimento em termos de capitalismo dependente, negando explicações que colocam o subdesenvolvimento como atraso, bem como se opõe à proposta de superação da condição de subdesenvolvimento por meio do apressamento do crescimento da economia. De acordo com o autor, a sociedade capitalista é aberta, com distribuição da 
população em classes sociais, havendo diferenciação entre elas, desigualdades sociais. Tal sociedade apresenta ajustes que regulam o privilégio econômico com consequências sociopolíticas e culturais.

A concepção do capitalismo dependente, apontada por Fernandes (2008), procura analisar as influências estruturais, bem como dinâmicas de caráter sócio global acerca da absorção e difusão do capitalismo no Brasil e, nessa análise, demarca a posição econômica de heteronomia no país, em aspectos estruturais e de funcionamento, a qual se manteve constante em diversos momentos da formação econômica do país. Então, o Brasil pode ser considerado historicamente um país de posição heteronômica, condicionado econômica e politicamente aos interesses do capital mundial, às políticas de ajustes impostas por agências internacionais, caracterizando-se também por manter um contexto interno de extremas desigualdades sociais (SANTOS, 2018).

Santos (2018) se direciona para um texto de Fernandes (1981), em que o autor pontua a existência de perda constante das riquezas existentes e que, em parte, foram sendo acumuladas. Ainda segundo o autor, ocorre apropriação capitalista, em que o excedente é dividido entre agentes econômicos internos e externos, com escoamento das riquezas para fora do país, intensificando a dependência deste em relação aos países de capitalismo central, bem como a redefinição de manifestações do subdesenvolvimento, com passagem de oligarquias tradicionais às elites mais abastadas, nas quais haveria representações diretas de parceiros externos. O escoamento de riquezas para fora do país de capitalismo dependente remete a países como a Índia que possui o Instituto Serum, referência no país de produção de vacinas para COVID-19 e que tem produção drenada primeiramente para os países capitalistas centrais.

As economias dos países de capitalismo dependente se estruturam em função das imposições do mercado mundial, de forma tal que os interesses econômicos somente predominam quando não desafinam das tendências de concentração de poder e do monopólio das vantagens econômicas que dominam o mercado mundial. Essa conformação atravanca o dinamismo político-econômico, impedindo a construção de uma ordem social nacional autônoma. Fernandes (1981) pontua que ocorre um processo nesses países de dupla articulação, em que, por um lado, tem-se a sociedade nacional subordinada aos países imperialistas e, por outro lado, há a necessidade de manter contexto interno de segregação social (SANTOS, 2018; FERNANDES, 2008).

Sampaio Jr. (1999 apud SANTOS, 2018) aponta que nos países com economia capitalista dependente perduram os mecanismos que possibilitam a acumulação primitiva e alerta para a distribuição desigual de progresso técnico, o que faz com que os produtores não sintam necessidade de tornar a inovação tecnológica a principal estratégia da concorrência.

\section{Constituição de 1988 e direito à saúde no Brasil}

O direito à saúde no Brasil foi reconhecido na Constituição de 1988 (TEODORO, 2018; PAIM, 2021). Até esse momento, as primeiras experiências das políticas sociais em saúde no Brasil (século XX) ocorreram baseadas em um modelo bismarckiano (lógica contributiva do seguro), sem uma política nacional de saúde, na qual as primeiras intervenções do Estado seguiam duas lógicas: a saúde pública que conduzia campanhas sanitárias e a medicina previdenciária (Instituto de Aposentadoria e Pensão - IAP, parcerias com saúde privada e filantrópica) (BAHIA, 1997; BEHRING; BOSCHETTI, 2011; MONTE-CARDOSO, 2013; OLIVEIRA; TEIXEIRA，2018; SANTOS, 2018).

O movimento da Reforma Sanitária Brasileira (RSB) que antecedeu à Constituição de 1988 apresentou em seu projeto uma relação para além da saúde, com dimensões como Seguridade Social, cidadania, questões educacionais e científico-tecnológicas (PAIM, 2008). Um marco desta nova constituição foi a proposição e instituição do SUS, instituindo o conceito de Seguridade Social e direitos a ela vinculados; outro marco foi o novo estatuto dos municípios como entes autônomos. Criou-se, também, um ciclo orçamentário que passou a comportar um orçamento da Seguridade Social (BEHRING; BOSCHETTI, 2011; NORONHA; SANTOS; PEREIRA, 2018; SANTOS, 2018).

$\mathrm{O}$ texto da nova constituição reflete a disputa de hegemonia, com avanços em alguns aspectos, como direitos sociais, mas mantendo traços conservadores. Apesar da instituição do SUS, manteve-se a tendência de crescimento das formas privadas de atenção à saúde mediante a convênios ou contratos de gestão com a iniciativa privada para prestação de serviço público (saúde complementar), além da atividade econômica privada (saúde suplementar). Não houve nacionalização da rede privada e filantrópica de hospitais, representando ambiguidade da implantação do SUS e mostrando a perspectiva híbrida da Constituição de 1988 (SANTOS, 2018; BEHRING; BOSCHETTI, 2011; CAMPOS, 2018).

\section{Pandemia ou sindemia?}

Horton (2020), na publicação: COVID-19 is not a pandemic, na revista Lancet, critica as intervenções focadas apenas nas linhas de transmissão viral, controlando, assim, a propagação do patógeno. Para 
o autor, esta é uma maneira simplista de combate à pandemia, para ele, duas categorias de doenças estão interagindo de forma sinérgica, em populações específicas: a infecção com a síndrome respiratória aguda grave (SARS-CoV-2) e uma série de doenças não transmissíveis (DNT). A associação dessas doenças, em um contexto de disparidade social e econômica, provoca interações que aumentam a suscetibilidade de uma pessoa, prejudicando o estado de saúde desta. Para o autor, o enfrentamento à pandemia significa combater as doenças crônicas negligenciadas, como hipertensão, obesidade, diabetes, doenças cardiovasculares e respiratórias crônicas, câncer, picadas de cobra, epilepsia, doença renal e doença falciforme, além de atenção às pessoas com maior vulnerabilidade social: idosos, comunidades étnicas negras, asiáticas e minoritárias; trabalhadores mal remunerados, entre outros. Segundo o autor, uma solução unicamente biomédica (vacina, medicamentos) para COVID-19 será insuficiente e falhará, será necessária a elaboração de políticas e programas de governo comprometidos com a dissolução de profundas desigualdades, para que sociedades e países estejam realmente protegidos da COVID-19 (HORTON, 2020).

Betto (2021), na revista Diálogos do Sul, estende esse conceito ao capitalismo sindêmico no Brasil, no qual há "acumulação privada da riqueza", como nas tentativas de privatização (parceria públicoprivada), subfinanciamento e precarização do SUS e de fornecimento de vacinas por clínicas privadas, em detrimento da não vacinação de boa parte da população que não seria contemplada com estas medidas.

Ainda segundo Betto (2021), as ações para conter o avanço da pandemia foram diferentes entre blocos e países no mundo; alguns, como a União Europeia, adotaram medidas sanitárias combinadas com redução do consumo e da mobilidade; a China optou pelo controle social associado à tecnologia. O Brasil e os Estados Unidos enfrentaram um impasse, um "falso dilema: deveriam salvar vidas ou a economia?", escolheram caminhos que desprotegiam vidas humanas, mas que mantinham a salvo a economia do país. Optaram pelo negacionismo da ciência, o que possibilitava prescindir recursos para compra de imunizantes e insumos sanitários, auxílios emergenciais, hospitais de campanha e relativizar medidas restritivas. Mais uma vez, o capitalismo se expressa de forma perversa, condenando os mais pobres à morte, pois não podem ficar em isolamento social, não receberam auxílio emergencial digno, não possuem em suas residências condições sanitárias básicas (água, sabonete, álcool gel, esgoto, diversos cômodos na casa...) para atender às medidas sanitárias e utilizam transporte público lotado, muitos trabalham informalmente nas ruas, tendo a renda diretamente afetada pela pandemia. Diante do exposto, considerando o contexto de vulnerabilidades e iniquidades no Brasil, a pandemia do COVID-19 caracteriza-se como uma sindemia.

\section{O SUS e o enfrentamento à pandemia da COVID-19}

A pandemia da COVID 19 demandou rápida reorganização dos serviços de saúde para seu enfrentamento. Esta resposta foi mais centrada nos serviços hospitalares, principalmente na abertura de novos leitos de Unidade de Terapia Intensiva (UTI) e compra de respiradores pulmonares. Medina et al. (2020) ressaltam a importância deste atendimento emergencial, porém alertam acerca da importância do investimento na Atenção Primária à Saúde (APS) para melhor resposta e controle da pandemia. Salientam a importância da Estratégia Saúde da Família para manter o contato e o vínculo com a comunidade em período de isolamento social à nível territorial.

Para as autoras, a atuação da APS no combate ao coronavírus ocorre a partir de quatro eixos: vigilância em saúde nos territórios, atenção aos usuários com COVID19, continuidade das ações próprias da APS e suporte social (apoio sanitário, financeiro, psicológico e social) a grupos vulneráveis (grupos de risco como idosos e portadores de comorbidades). Nas considerações finais, as autoras alertam para o fracasso do enfrentamento à pandemia a nível mundial, quando o cuidado foi focado a nível individual e hospitalar. Ressaltam a necessidade de abordagem mais territorializada, comunitária e domiciliar e de uma APS "com toda sua potencialidade" (MEDINA et al., 2020).

Para Giovanella et al. (2020), a falta de priorização da rede de atenção básica, neste caso, da Estratégia Saúde da família (ESF), vem ocorrendo desde 2017, por intermédio de ações como redução das equipes de agentes comunitários de saúde e retirada dos médicos do Programa Mais Médicos, flexibilização de carga horária de profissionais, em que a ESF deixa de ser prioridade, extinção do Núcleo Ampliado de Saúde da Família e Atenção Básica (NASF-AB), falta de incentivo à abordagem territorial, com financiamento baseado em número de cadastrados. De acordo com a Rede de Pesquisa em Atenção Primária à Saúde da ABRASCO (2018), outras questões também fragilizam a ESF, como precarização das relações trabalhistas com contratação de organizações sociais e outras formas de privatização da gestão de unidades básicas de saúde, mercantilizando as relações e fragilizando vínculos, baixa integração entre a rede regionalizada, comprometendo a coordenação, continuidade e fragmentação do cuidado.

Collucci (2020) pontua que as cidades com atenção primária organizada, por meio das equipes de Saúde da Família, conseguiram, além da demanda para COVID-19 (testagem em domicílio, acompanhamento 
de casos leves), acompanhar outras doenças e agravos não relacionados. Algumas equipes se utilizaram também do recurso da telemedicina, como por exemplo, numa Clínica da Família, em Manguinhos, no Rio de Janeiro e numa UBS de Ceilândia, no Distrito Federal, nas quais foi ofertado o cuidado a distância via celular como enfrentamento às restrições do acesso presencial na pandemia (AMARAL; JUNIOR, 2020; ALENCAR; SOUZA, 2021).

A Emenda Constitucional 95 congelou o teto de gastos públicos, incluindo a saúde, por 20 anos. Para o ano de 2021, é previsto pelo Conselho Nacional de Saúde (CNS) perda de até 35 milhões de reais para a saúde (COLLUCCI, 2021). Para um sistema que já é historicamente subfinanciado, este déficit pode ser catastrófico; ainda é preciso considerar o agravamento de doenças, como câncer, diabetes, hipertensão que não foram tratados/assistidos durante a pandemia e que trarão consequências futuras para o sistema de saúde.

A Lei de Responsabilidade Fiscal (LRF), criada em março de 2000, limitou os gastos com pessoal pelos entes federados; nela, os gastos com folha de pagamento não podem exceder $60 \%$ do orçamento da área. Em consequência disso, houve restrições das políticas sociais nacionais. Na saúde, motivadas pela contensão de custos, houve ampliação da terceirização das contratações de força de trabalho. A LRF, associada à falta de carreira nacional do SUS, comprometeu a organização do trabalho no sistema público de saúde e a integração do SUS (SANTOS, 2018; BEHRING, 2008).

\section{Iniquidades na distribuição e no acesso às vacinas contra COVID-19}

Neste ensaio, também se buscou relacionar o conceito de capitalismo dependente de Fernandes (2008), dando enfoque a reflexões acerca da relação deste com as iniquidades na distribuição e no acesso às vacinas (e as tecnologias de produção) contra COVID19 no Brasil, sem pretensões de esgotar tal debate complexo. Faz-se necessário reconhecer a limitação desse recorte temático, visto que há a existência de outros fatores no cenário brasileiro que constituem entraves ao acesso dos imunizantes para COVID-19, mas que não representaram o foco do presente ensaio, como crise política, presença de lideranças governamentais que são negacionistas do vírus e da ciência, erros nas negociações de aquisição das vacinas, movimento antivacina, tensões diplomáticas com a China que culminou no atraso do envio de insumos à Fiocruz e ao Instituto Butantan para produção de imunizantes contra COVID-19.

Por que o Brasil depende da importação de insumos, como o Ingrediente Farmacêutico Ativo
(IFA) vindo da China para produção de vacinas? Essa dependência de progresso técnico, característica dos países de capitalismo dependente, poderia ser superada no Brasil? A Fiocruz e o Instituto Butantan são referências científicas em produção de imunizantes, por que, então, a dependência externa? É possível que o Brasil tenha potencial científico para produção autônoma de imunizantes, mas, provavelmente, esse fato colidiria com as imposições e os interesses do capitalismo central.

De acordo com Castro (2021), o contexto global se apresenta marcado por iniquidades na distribuição e no acesso às vacinas contra COVID-19. A autora aponta para práticas de alguns países, principalmente do norte global, de aquisição de grandes estoques desses imunizantes por meio da celebração antecipada de contratos com laboratórios farmacêuticos, em uma corrida que privilegia uma minoria de países com maior poder de compra, limitando, assim, as possibilidades de que ocorra acesso equânime aos imunizantes pelos demais países com menos poder de barganha diante do mercado farmacêutico mundial, o qual está alinhado aos interesses do capital. Relata que, em alguns desses países, a exemplo o Canadá, houve aquisição de unidades de vacinas em quantitativo superior ao necessário para vacinação de toda população, o que contrasta com a realidade de muitos países de capitalismo dependente, do sul global, os quais, a princípio, não conseguiram doses suficientes para imunização dos profissionais de saúde.

Segundo Bermudez e Bermudez (2021), a disputa de mercado, travada atualmente, e a corrida pela aquisição antecipada do estoque mundial de vacinas contra COVID-19 são preocupantes, e mereceram atenção do diretor geral da Organização Mundial da Saúde (OMS) e da diretora executiva do Fundo das Nações Unidas para a Infância (UNICEF), os quais fizeram declaração em conjunto, tocando na gravidade dessa situação do acesso desigual às vacinas contra COVID-19. Ambos destacaram que dez países detinham $75 \%$ do estoque da produção desses imunizantes, o que implicava restrição de acesso a cerca de 130 países. Os países imperialistas representam $16 \%$ da população mundial e, mesmo sendo minoria, já conseguiram comprar antecipadamente $60 \%$ da produção de imunizantes contra COVID-19 no ano de 2021, usando dos privilégios econômicos e se beneficiando da lógica do mercado farmacêutico que atende aos interesses do capital mundial e, em consequência, possivelmente deixam grupo que abarca os 84 países mais pobres a esperar por 2022, 2023, ou até 2024 , para conseguirem vacinar suas populações.

Diante das iniquidades expostas anteriormente, algumas iniciativas têm sido feitas no cenário internacional, com intuito de estimular o acesso equânime a medicamentos e tecnologias em saúde direcionadas ao combate à COVID-19, reconhecendo 
a imunização como bem público global. É valido destacar como exemplos dessas iniciativas: as Resoluções A/RES/74/270 e A/RES/74/274, aprovadas na Assembleia Geral das Nações Unidas, e a Resolução WHA 73.1, acatada pela Assembleia Mundial de Saúde (BERMUDEZ; BERMUDEZ, 2021).

As estratégias mundiais que buscam reduzir as iniquidades na distribuição e no acesso às vacinas contra Covid-19 constituem importante chamado de solidariedade para o combate à pandemia, mas não tocam em questões estruturais, como a que foi trazida no conceito de capitalismo dependente, abordado por Fernandes (2008), e que é apenas uma das múltiplas facetas que podem contribuir para compreensão do motivo dessas iniquidades.

Faz-se necessário refletir acerca das diversas facetas que constituem a malha dessa densa problemática e, para tanto, seguem algumas questões intrigantes, no intuito de suscitar reflexões outras, as quais não foram abordadas no escopo deste ensaio, devido ao recorte escolhido, mas que mantém relevância: Por que o Brasil está atrasado em relação à vacinação, mesmo contando com o potencial do Sistema Único de Saúde e a experiência do Programa Nacional de Imunização? Como enfrentar o avanço do neoliberalismo sobre as políticas de acesso universal à saúde? Como recuperar a soberania sanitária brasileira em tempos pandêmicos?

\section{Considerações finais}

Voltando ao questionamento inicial realizado no título do texto: o que tem a ver o capitalismo dependente de Florestan Fernandes, o subfinanciamento do SUS, as iniquidades na distribuição e no acesso às vacinas e a sindemia do COVID 19? Pode-se observar que o capitalismo dependente, sendo heteronômico, favorece a desigual distribuição de renda, refletindo nas condições de vida e de saúde da população, principalmente as não favorecidas, sendo agravadas por esta (sindemia).

No Brasil, o enfrentamento à COVID-19 expôs mazelas existentes, principalmente as sociais, incluindo o acesso à saúde. Segundo Moraes (2020), existem 15.754 leitos de UTI para 48 milhões de brasileiros que possuem plano de saúde (32,8 leitos por 100 mil habitantes). Comparando com o SUS, são nove leitos por 100 mil habitantes após ampliação do número de leitos durante a pandemia; anteriormente eram 14.869 (7 leitos por 100 mil habitantes). Estas questões foram refletidas nas taxas de mortalidade, sendo maiores nas UTI da rede pública (COLLUCCI, 2021).

O SUS, mesmo com todas as fragilidades (subfinanciamento crônico, ataque da mídia, precarização da força de trabalho, saúde complementar), conseguiu responder à pandemia da COVID-19, evitando colapso de todo sistema assistencial do país. Segundo dados do Ministério da Saúde (MS), 15.000 novos leitos foram criados exclusivamente para atender à demanda causada pela pandemia, mediante ações de estados, municípios e verbas do governo federal (COLLUCCI, 2021). Desta forma, é fundamental a defesa de um SUS forte, com potencialidade, mas, principalmente, a luta por uma sociedade mais justa e igualitária, que refletirá, não somente na saúde, mas em todas as esferas da sociedade.

\section{Referências}

ALENCAR, S.S.; SOUZA, F.A. Uso do WhatsApp por uma equipe de Saúde da Família como estratégia para lidar com demandas administrativas. Health Residencies Journal, Brasília, v. 2, n. 9, p.169-82, fev. 2021.

AMARAL, L.M.; JUNIOR, J.E.T. Cuidado remoto na APS: experiência do uso do celular em uma equipe de Saúde da Família de área de favela durante a crise da COVID-19. Rev. APS, Juiz de Fora, v. 2, n. 9, p.706-16, set. 2020.

BAHIA, L. Os planos e seguros privados no Brasil: notas sobre o objeto e procedimento de estudo. Cad. Saúde Colet., Rio de Janeiro, v. 5, n. 2, p. 105-22, jul./dez. 1997

BEHRING, E.R. Brasil em contra-reforma: desestruturação do estado e perdas de direito. 2. ed. São Paulo: Cortez, 2008.

BEHRING, E. R.; BOSCHETTI, I. Política Social: fundamentos e história. 9. ed. São Paulo: Cortez, 2011.

BERMUDEZ, L.; BERMUDEZ, J. Covid-19: os desafios do acesso a tecnologias no mundo globalizado. Informe ENSP, p. 1-3, 2021.

BETTO, F. Frei Betto: crise do coronavírus não é uma pandemia, mas uma sindemia. Diálogos do Sul, São Paulo, 20 jan. 2021. Disponível em: https:// dialogosdosul.operamundi.uol.com.br/brasil/68181/frei-betto-crise-docoronavirus-nao-e-uma-pandemia-mas-uma-sindemia. Acesso em: 21 jun. 2021.

BRASIL. Ministério da saúde. Painel Coronavirus (COVID-19). Brasília, 2021. Disponível em: https://covid.saude.gov.br/. Acesso em: 23 jun. 2021.

CAMPOS, G. W. S. Modo de co-produção singular do sistema único de saúde: impasses e perspectivas. In: SANTOS, J. A. A ampliação do processo de privatização da saúde pública no Brasil. São Paulo: Hucitec, 2018. 249 p.

CASTRO, R. Vacinas contra a Covid-19: o fim da pandemia ? Physis, Rio de Janeiro, v. 31, n. 1, p. 1-5, 2021. Disponível em: https://www.scielo.br/j/ physis/a/m4PGYb7TPWgCS3X8wMSXHtc/?lang=pt. Acesso em: 23 jun. 2021.

CIORRA, H. Agenda saúde na cidade. IEPS - Instituto de Estudos para Políticas de Saúde. 15 out. 2020. Disponível em: https://ieps.org. br/2020/10/15/agenda-saude-na-cidade/. Acesso em: 14 jun. 2021.

COLLUCCI, C. A imagem do SUS depois da pandemia. In: CONASS. Reflexões e futuro. Brasília, DF: CONASS, 2021. p. 282-293. (Coleção Covid-19, v. 6).

COLLUCCI, C. Com saúde básica, cidades conseguem frear Covid-19. Folha de São Paulo, São Paulo, 4 jul. 2020. Disponível em: https://www1. folha.uol.com.br/equilibrioesaude/2020/07/com-saude-basica-cidadesconseguem-frear-covid-19.shtml. Acesso em: 08 jul. 2021.

FERNANDES, F. Capitalismo dependente e classes sociais na América Latina. 3. ed. Rio de Janeiro: Zahar, 1981.

FERNANDES, F. O estudo sociológico do subdesenvolvimento econômico. In: Sociedade de classes e subdesenvolvimento. 5. ed. São Paulo: Global, 2008 .

FRAGA, A. Reforçando o SUS. Folha de São Paulo, São Paulo, 26 set. 2020. Disponível em: https://www1.folha.uol.com.br/colunas/arminiofraga/2020/09/refor-cando-o-sus.shtml. Acesso em: 22 jun. 2021.

GIOVANELLA, L. et al. A contribuição da atenção primária à saúde na 
rede SUS de enfrentamento à Covid-19. Saúde debate, p.1-21, 2020. DOI: 10.1590/SciELOPreprints.1286. Disponível em: https://preprints.scielo.org/ index.php/scielo/preprint/view/1286. Acesso em: 08 jul. 2021.

HORTON, R. Offline: COVID-19 is not a pandemic. The Lancet, v. 396, n. 10255 , p. 874, 2020.

MEDINA, M. G. et al. Atenção primária à saúde em tempos de COVID19: o que fazer? Cad. Saúde Colet., v. 36, n. 8, 2020. DOI: https://doi. org/10.1590/0102-311X00149720. Disponível em: https://www.scielosp. org/article/csp/2020.v36n8/e00149720/pt/. Acesso em: 22 jun. 2021.

MENDES, E. V. Desafios do SUS. Brasília, DF: CONASS, 2019.

MONTAÑO, C. E. O projeto neoliberal de resposta à "questão social" e a funcionalidade do "terceiro setor". Lutas Sociais, n. 8, p. 53-64, 2002.

MONTE-CARDOSO, F. A saúde entre os negócios e a questão social: privatização, modernização e segregação na ditadura civil-militar (19641985). 2013. 207 p. Dissertação (Mestrado em Saúde Coletiva). Faculdade de Ciências Médicas, Universidade Estadual de Campinas, Campinas, SP, 2013.

MORAES, T. Pandemia reforça importância do SUS. JCNET, Bauru, SP, 19 jul. 2020. Disponível em: https:/www.jcnet.com.br/noticias/ geral/2020/07/730017-pan-demia-reforca-importancia-do-sus.html. Acesso em: 22 jun. 2021.

NORONHA, J. C.; SANTOS, I. S.; PEREIRA, T. R. Relações entre o SUS e a saúde suplementar: problemas e alternativas para o future do sistema universal. In: SANTOS, J. A. A ampliação do processo de privatização da saúde pública no Brasil. São Paulo: Hucitec, 2018. 249 p.

OLIVEIRA, J. A. A.; TEIXEIRA, S. M. F. (IM) Previdência social: 60 anos de história da previdência no Brasil. In: SANTOS, J. A. A ampliação do processo de privatização da saúde pública no Brasil. São Paulo: Hucitec, 2018. 249 p.

PAIM, J. S. A Covid-19, a atualidade da reforma sanitária e as possibilidades do SUS. In: CONASS. Reflexões e futuro. Brasília, DF: CONASS, 2021. p. 310-324. (Coleção Covid-19, v. 6).

PAIM, J. S. Reforma sanitária brasileira: contribuição para a compreensão e crítica. Salvador/Rio de Janeiro: EDUFBN FIOCRUZ, 2008.

PAULO NETTO, J.; BRAZ, M. Economia política: uma introdução crítica. 5. ed. São Paulo: Cortez, 2009.

REDE DE PESQUISA EM ATENCC̃̃O PRIMÁRIA À SAÚDE DA ABRASCO. Contribuição para uma agenda política estratégica para a atenção primária à saúde no SUS. Saúde debate, v. 42, n. especial, p. 406430, 2018.

SAMPAIO JR, P. A. Globalização e reversão neocolonial: o impasse brasileiro. In: VÁSQUEZ, G. H. (Comp.) Filosofia y teorias políticas entre la crítica y la utopía, Buenos Aires: CLACSO, 2007. p. 143-155.

SANTOS, J. A. A ampliação do processo de privatização da saúde pública no Brasil. São Paulo: Hucitec, 2018. 249 p.

TEODORO, R. A teoria sanitária e o momento corporativo: a crítica de um desafio não superado. In: FLEURY, S. (Org). Teoria da reforma sanitária: diálogos críticos. Rio de Janeiro: Editora Fiocruz; 2018. p. 183-219. 